\title{
Desenvolvimento do Reuni: crítica à sua implantação e sua relação econômica
}

\author{
André Moura Blundi Filardi \\ Universidade Federal de São Carlos
}

\section{Resumo}

Este artigo procura analisar e discutir parte das consequências da implantação do Programa de Apoio a Planos de Reestruturação das Universidades Federais (Reuni) no Brasil a partir de sua implantação em 2007. Para tanto faz um recorte que busca, por meio de documentos oficiais, números da expansão das universidades, estatísticas, dados da expansão e da reestruturação e a discussão destes, a fim de desvelar um viés econômico e administrativo do Reuni que não está escrito em seus artigos e em suas Diretrizes Gerais. Mais que um simples programa, o Reuni se mostra como uma peça-chave na recomposição do capital produtivo e na transformação das formas de administração do Estado e das políticas públicas.

Palavras-chave: Reuni. Universidades federais. Expansão. 


\section{The development of Reuni: a review of its implementation and economic relations}

This article aims at analyzing and discussing some consequences of the implementation of the Support Program for Restructuring Plans of Federal Universities (Reuni), in Brazil, since its implementation in 2007. To that end, the approach is based on official documents, numbers taken from the expansion of universities, statistics, information about expansion and restructuring and their discussion, in order to reveal an economical and administrative bias of Reuni that is not written in its articles and General Guidelines. More than a simple program, Reuni is a key part in recomposition of productive capital and the transformation of the methods of administration of the state and of public policies.

Keywords: Reuni. federal Universities. Expansion.

\section{Desarrollo del Reuni: crítica a su aplicación y su relación con la economía}

Este artículo trata de analizar y discutir parte de las consecuencias de la aplicación en Brasil del Programa de Apoyo a la Reestructuración de Universidades Federales (Reuni), a partir de su implementación, en 2007. Para eso hace un recorte que busca, por medio de documentos oficiales, números de expansión de las universidades, estadísticas, datos de la expansión y de la reestructuración, y la discusión de los mismos, develar una veta económica y administrativa del Reuni que no está escrita en sus artículos y directrices generales. Más que un simple programa el Reuni se muestra una pieza clave en la recomposición del capital productivo y en la transformación de las formas de administración del estado y de políticas públicas.

Palabras-clave: Reuni. Universidades federales. Expansión. 
O governo brasileiro, no segundo mandato do presidente Lula, em abril de 2007, instituiu o Programa de Expansão e Reestruturação das Universidades Federais no Brasil (Reuni). Este programa que, em vários aspectos, se mostrou mais do que um simples programa propôs uma reformulação das universidades públicas federais no que se refere ao seu financiamento, aos seus planos pedagógicos, às suas políticas de inclusão, à mobilidade estudantil, às formas de ingresso na universidade, ao número de discentes por professor por disciplina, à taxa de conclusão de curso, entre outros fatores. 0 governo declarou na época, como argumento para a necessidade urgente do programa, que havia no Brasil uma estrutura universitária atuando abaixo dos níveis de eficiência almejados pela própria administração pública e que o uso material e humano e das estruturas das universidades estava aquém de um ideal considerado pelo próprio governo e pelo Ministério da Educação (MEC). Assim, se promulgou o decreto que estabeleceu o Reuni:

DECRETO Nº - 6.096, DE 24 DE ABRIL DE 2007.

Institui o Programa de Apoio a Planos de Reestruturação e Expansão das Universidades Federais (Reuni).

O PRESIDENTE DA REPÚBLICA, no uso da atribuição que the confere o art. 84, inciso VI, alínea "a", da Constituição, e considerando a meta de expansão da oferta de educação superior constante do item 4.3.1 do Plano Nacional de Educação, instituído pela Lei $n^{\circ} 10.172$, de 9 de janeiro de 2001,

DECRETA:

Art. $1^{\circ}$ Fica instituído o Programa de Apoio a Planos de Reestruturação e Expansão das Universidades Federais (Reuni), com o objetivo de criar condições para a ampliação do acesso e permanência na educação superior, no nível de graduação, pelo melhor aproveitamento da estrutura física e de recursos humanos existentes nas universidades federais. (Brasil, 2007 a, p. 7).

Desta maneira, percebemos de início que o governo demonstrou que seus intuitos principais com o referido programa era a otimização dos recursos das universidades, a ampliação do uso de suas estruturas e recursos humanos e ampliação e expansão do sistema de ensino superior federal. Mas destacamos que estes objetivos foram traçados a partir da lógica da administração gerencial e da eficiência, em que a "otimização de recursos" é peça fundamental da proposta. Procuraremos mostrar neste artigo, por meio de dados apresentados e analisados, que há um sentido econômico e político nestes objetivos que são interdependentes e interligados à atual conjuntura da economia capitalista e à sua inserção no Brasil.

0 artigo $2^{\circ}$ deste decreto presidencial mostra as diretrizes principais do programa. Em primeiro lugar, o Ministério da Educação (MEC) traz ' '...a redução 
das taxas de evasão, ocupação de vagas ociosas e aumento de vagas de ingresso, especialmente no período noturno '(Brasil, 2007 a, p. 7). Assim, o governo mostra, novamente, que sua preocupação principal, com o programa, é a melhor utilização dos recursos das universidades. Preocupa-se, também, com o fato de que uma parcela pequena da população brasileira, em idade para cursar o ensino superior, está matriculada neste nível de ensino. Em comparação com países da Organização para Cooperação e Desenvolvimento Econômico (OCDE), grupo de países industrializados, além de outros países emergentes, o Brasil exibia os piores índices de matrícula bruta neste nível de ensino. Assim, o Brasil, quando comparado aos níveis de eficiência e qualificação da mão-de-obra, era, e ainda é, um dos piores neste ranking, ou seja, temos dificuldades estruturais e humanas (recursos humanos e mão-de-obra qualificada) de inserção na economia mundializada.

Segundo o governo, em seu Plano de Desenvolvimento da Educação (PDE) de 2007:

A educação superior baliza-se pelos seguintes princípios complementares entre si: i) expansão da oferta de vagas, dado ser inaceitável que somente $11 \%$ de jovens, entre 18 e 24 anos, tenham acesso a esse nível educacional, ii) garantia de qualidade, pois não basta ampliar, é preciso fazê-lo com qualidade, iii) promoção de inclusão social pela educação, minorando nosso histórico de desperdício de talentos, considerando que dispomos comprovadamente de significativo contingente de jovens competentes e criativos que têm sido sistematicamente excluídos por um filtro de natureza econômica. (Brasil, 2007 b, p. 26)

Observa, também, que, pela realidade social brasileira, na qual boa parte dos jovens ingressa cedo no mercado de trabalho, se faz necessária uma maior oferta de cursos de graduação no período noturno, já que, desta maneira, incluiria esta parcela de jovens que iniciam sua vida profissional antes de obterem o curso superior, ou que o fazem concomitantemente. Neste sentido, o diagnóstico que o MEC elaborou da realidade da educação superior brasileira e da própria realidade social é correto, em primeiro momento, segundo nossa análise.

Os meios para a transformação qualitativa e concreta desta realidade é que são discutíveis, mesmo porque o sistema de educação superior demanda investimentos de grande monta para sua manutenção e, ainda mais, para sua transformação, já que ocorre uma precarização das condições de financiamento e manutenção destas instituições desde a Reforma do Estado - transformação nas esferas de administração pública buscando aumento da eficiência e redução dos custos do Estado, promulgada a partir do governo Fernando Henrique Cardoso e do estabelecimento do Ministério da Administração e Reforma do Estado (Mare) 
em meados da década de 1990.

Existem a cultura institucional e a organização acadêmica de cada uma destas universidades, as administrações - Reitorias e Pró-reitorias - e, principalmente, os docentes, que não estavam dispostos a, simplesmente, cumprir uma demanda governamental sem que fossem discutidos substancialmente quais seriam os meios concretos para estas implantações. Ou seja, o programa sofreu com a resistência da comunidade acadêmica, acostumada a perceber e a denunciar a falta de planejamento e concretude dos planos governamentais para as universidades federais. 0 segundo inciso do artigo $2^{\circ}$ do Reuni promulga:

A ampliação da mobilidade estudantil, com a implantação de regimes curriculares e sistemas de títulos que possibilitem a construção de itinerários formativos, mediante o aproveitamento de créditos e a circulação de estudantes entre instituições, cursos e programas de educação superior. (Brasil, 2007 a, p. 7)

Ou seja, possibilidades de troca de discentes e aproveitamento curricular de uma instituição para outra, no sentido de não se "perder" um trabalho acadêmico que tenha sido iniciado em outra instituição ou mesmo em outro país. As trocas de experiências acadêmicas, o aprendizado de outras línguas e outras culturas seriam algumas "necessidades" da formação profissional completa, ou esperada, no contexto da mundialização do capital que está em operação no atual cenário do sistema econômico mundial. As corporações se beneficiam sobremaneira com a formação de uma mão-de-obra, principalmente intelectual, que se ajusta muito bem à realidade econômica do mercado global.

Nesse cenário, a mobilidade estudantil emerge como um importante objetivo a ser alcançado pelas instituições participantes do Reuni não só pelo reconhecimento nacional e internacional dessa prática no meio acadêmico, mas fundamentalmente por se constituir em estratégia privilegiada de construção de novos saberes e de vivência de outras culturas, de valorização e de respeito ao diferente:

0 exercício profissional no mundo atual requer aprendizagens múltiplas e demanda interseção com saberes e atitudes construídos a partir de experiências diversas que passam a ser, cada vez mais, objeto de valorização na formação universitária. (Brasil, 2007 a, p. 5)

Faz-se interessante ressaltar como, a partir da necessidade econômica de formação profissional, o intercâmbio cultural e as possibilidades do aproveitamento dos recursos humanos para a reprodução do capital, perante a economia capitalista atuante em âmbito mundial, se coadunam de maneira 
justa e própria com um discurso de "construção de novos saberes e de vivência de outras culturas, de valorização e de respeito ao diferente". Esta mesma realidade se fez presente no que foi denominado "Processo de Bolonha":

0 Processo de Bolonha é um movimento que surgiu de fora da universidade, sob o comando dos dirigentes políticos da União Europeia (UE) e está possibilitando um novo desenho de regulação e de reforma na educação superior nesse bloco. A Declaração de Bolonha (1999) estabeleceu as seguintes linhas de ação: adoção de um sistema de graus de acessível leitura e comparáveis no âmbito da UE; implementação de um sistema de ensino baseado em dois ciclos; promoção da maior mobilidade de estudantes, professores e investigadores; estabelecimento de um sistema de acumulação e transferência de créditos; promoção da cooperação europeia para avaliação da qualidade do ensino superior; promoção da atratividade do espaço europeu de ensino superior. A partir de Bolonha, verifica-se: diversificação e hierarquização das IES; aumento do financiamento privado e da parceria com o sistema produtivo; diminuição da durabilidade dos cursos mediante a implantação dos ciclos; modelo gerencial de administração para as IES; sistemas de avaliação da qualidade e credenciamento institucional; criação do Espaço Europeu de Ensino Superior (EEES) e do Espaço Europeu da Investigação (EEI). Esse movimento tem como meta a atratividade internacional de estudantes e pesquisadores tanto interna como externamente, assim como, a adaptação da formação da graduação ao mercado de trabalho visando alavancar e tornar a Europa mais competitiva no mercado global. (Ferreira, 2010, p.5)

Por meio da divulgação de novas "tecnologias de aprendizagem" e "novas possibilidades de formação", permite-se que haja uma circulação da formação da mão-de-obra que beneficia sobremaneira os esforços das corporações transnacionais na Europa em sua busca por recursos humanos competentes, baratos e "globalizados". Além disso, houve uma expansão desta ideologia para as universidades dos países em desenvolvimento no sentido de inseri-las nas perspectivas e nas possibilidades da produção. 0 conhecimento e a ciência se estão atrelando à esfera da produção e do consumo, conforme análise da professora Suely Ferreira:

Nas últimas décadas do século XX e no início dos anos 2000, têm-se observado mudanças substantivas nas concepções e nos papéis sociais das universidades. Esse movimento dialético que envolve tanto os aspectos internos como externos das universidades remete a situá-la não somente no contexto nacional, mas no cenário da internacionalização da educação superior. Discutir as novas concepções e finalidades sociais que estão sendo reclamadas para as universidades públicas no contexto da reestruturação produtiva do capital em âmbito global faz-se necessário, na medida em que o papel social da universidade vem ganhando significativa centralidade, ao ser 
exigida uma nova relevância social na e para a sociedade da economia do conhecimento, expressão propalada que assume a perspectiva de que sociedade e economia devem estar assentadas no conhecimento como estratégia de competitividade, tanto no cenário local como no regional e no internacional. (Ferreira, 2010, p.1)

Em seguida, o decreto do Reuni trouxe a discussão sobre “...a revisão da estrutura acadêmica, com a reorganização dos cursos de graduação e atualização de metodologias de ensino-aprendizagem, buscando a elevação da qualidade". (Brasil, 2007 a, p. 7). Aqui, novamente, se visualiza a questão das novas metodologias. A necessidade destas apenas é justificável em um cenário no qual o objetivo da educação superior se transforma. Por exemplo, nas diretrizes do programa, aparece a discussão da necessidade de os cursos de graduação trabalharem a interdisciplinaridade e a flexibilização e de estes cursos estarem articulados ao que se pesquisa na pós-graduação. Essas exigências serviriam ao aumento da qualidade, mas é questionável, em termos pedagógicos, a discussão da maior ou menor qualidade da educação a partir de seus métodos.

Esta formação "flexibilizada" serviria à necessidade de um profissional mais flexibilizado, segundo nossa análise. A interdisciplinaridade serve ao estabelecimento de cursos com uma grade inicial comum, de modo que a especialização se dá em caráter posterior, e se "otimiza" o "recurso humano" professor. A proclamada "qualidade almejada", que flexibiliza a formação e os projetos pedagógicos dos cursos de graduação, no entanto, é compreendida por nós como relacionada aos princípios da educação terciária, tal como se aponta com o discurso oficial:

A qualidade almejada para este nível de ensino tende a se concretizar a partir da adesão dessas instituições ao programa e às suas diretrizes, com o consequente redesenho curricular dos seus cursos, valorizando a flexibilização e a interdisciplinaridade, diversificando as modalidades de graduação e articulando-a com a pós-graduação, além do estabelecimento da necessária e inadiável interface da educação superior com a educação básica. (Brasil, 2007 a, p. 5)

Assim, questionamos a concretização da melhoria dos cursos de graduação das universidades federais a partir da expansão intensificada de suas vagas. Inclusive, questionamos o "redesenho curricular" dos cursos e a articulação com a educação básica. Como poderíamos trazer transformações substanciais deste porte se não houve tempo hábil para o planejamento do programa? Com isso, o intuito principal concreto do Reuni, que é a maior articulação e a maior inserção do ensino superior do Brasil, e de sua economia, na esfera da mundialização do capital, começa a se desvelar. 
Argumentamos, neste sentido, que certos aspectos da formulação do programa estão carregados de uma ideologia e de um discurso que serve mais à sua própria formulação do que à concretização de fato destas mudanças. A distância entre o que está formulado e os objetivos concretos do programa deve ser analisada a partir destas contradições: discursos e ideologias que ficam evidentes, inclusive pela análise dos dados e documentos disponíveis, como, por exemplo, destes artigos extraídos do próprio programa Reuni:

\section{Art. 1}

§ 100 Programa tem como meta global a elevação gradual da taxa de conclusão média dos cursos de graduação presenciais para noventa por cento e da relação de alunos de graduação em cursos presenciais por professor para dezoito, ao final de cinco anos, a contar do início de cada plano.

Art. $3^{\circ} 0$ Ministério da Educação destinará ao Programa recursos financeiros, que serão reservados a cada universidade federal, na medida da elaboração e apresentação dos respectivos planos de reestruturação, a fim de suportar as despesas decorrentes das iniciativas propostas (...).

$\S 1^{\circ} 0$ acréscimo de recursos referido no inciso III será limitado a vinte por cento das despesas de custeio e pessoal da universidade, no período de cinco anos de que trata 0 art. $1^{\circ}, \S 1^{\circ}$.

$\S 3^{\circ} 0$ atendimento dos planos é condicionado à capacidade orçamentária e operacional do Ministério da Educação.

Art. $6^{\circ}$ A proposta, se aprovada pelo Ministério da Educação, dará origem a instrumentos próprios, que fixarão os recursos financeiros adicionais destinados à universidade, vinculando os repasses ao cumprimento das etapas. (Brasil, 2007a, p. 1)

O financiamento da expansão proposta pelo Reuni viria de fontes do MEC na medida em que cada universidade elaborasse um plano de reestruturação e se adaptasse às exigências do governo. Ou seja, há uma necessária submissão das entidades ao governo quando se trata do plano de expansão e reestruturação. Este deve ser moldado de acordo com o que o MEC entende como melhor eficiência do uso das instalações e recursos humanos para as universidades. Deveria haver uma "otimização" do trabalho que, segundo nossa análise, poderia levar à precarização das condições de trabalho nas universidades e à intensificação do trabalho docente. Mas há que se ressaltar que as universidades federais, há tempos trabalhando em um cenário de contenção de despesas e investimento, viram no Reuni uma possibilidade de expansão e reestruturação que as poderia beneficiar de algum modo. A previsão do acréscimo orçamentário proposto pelo Reuni é exposto nas tabelas abaixo: 
Tabela 1 - Previsão de acréscimo orçamentário a partir do Reuni

\begin{tabular}{c|c|c|c|c|c}
\hline \multicolumn{6}{|c}{ Previsão de acréscimo orçamentário a partir do Decreto $\mathrm{n}^{\circ}$} \\
(valores em milhares de reais) \\
\hline Ano & 2008 & 2009 & 2010 & 2011 & 2012 \\
\hline Investimento & 305.843 & 567.671 & 593.231 & 603.232 & \\
\hline Custeio/Pessoal & 174.157 & 564.274 & 975.707 & 1.445 .707 & 1.970 .205 \\
\hline Total & 480.000 & 1.131 .918 & 1.568 .938 & 2.048 .939 & 1.970 .205 \\
\hline
\end{tabular}

Fonte: Brasil Sesu/MEC/Diretrizes Gerais do Reuni, 2007, p. 13.

Tabela 2 - Execução orçamentária geral do programa Reuni em 2008

\begin{tabular}{|c|c|c|c|c|c|c|c|c|c|}
\hline \multirow{3}{*}{$\begin{array}{l}\text { IFES } \\
\text { Total }\end{array}$} & \multicolumn{3}{|c|}{ PACTUADO } & \multicolumn{4}{|c|}{ DISPONIBILIZADO } & \multirow{2}{*}{\multicolumn{2}{|c|}{$\begin{array}{c}\text { DIFERENÇA: } \\
\text { Disponibilizado - } \\
\text { Pactuado } \\
\text { TOTAL } \\
\text { exceto Bolsa } \\
\text { Capes }\end{array}$}} \\
\hline & $\begin{array}{c}\text { Custeio } \\
\mathrm{AE}+\mathrm{UBC}\end{array}$ & Investimento & $\begin{array}{l}\text { TOTAL } \\
\text { exceto Bolsa } \\
\text { Capes }\end{array}$ & Custeio & Investimento & $\begin{array}{l}\text { TOTAL } \\
\text { exceto Bolsa } \\
\text { Capes }\end{array}$ & $\%$ & & \\
\hline & 65.383 .199 & 431.615 .330 & 496.998 .529 & 76.220 .896 & 415.661 .444 & 491.882 .340 & $99 \%$ & -5.116 .189 & $-1,0 \%$ \\
\hline
\end{tabular}

Fonte: Brasil MEC/Sesu, 2008, p.12.

O governo vincula as verbas que serão utilizadas no plano de expansão de cada universidade ao cumprimento de metas e à elaboração de um plano para o cumprimento destas metas. É um acordo direto entre o MEC e a reitoria de cada universidade, mas que está condicionado à existência de verbas e a um esforço de cada Ifes para que as verbas deem conta da expansão das vagas, da construção de prédios, de estabelecimento de novos cursos, da elaboração e construção de novos campi, da interiorização das universidades federais pelo Brasil.

Para cada universidade federal que aderir a este "termo de pactuação de metas", ou seja, um contrato de gestão com o MEC, o governo "promete" um acréscimo de recursos limitado a vinte por cento das despesas de custeio e pessoal. Entretanto, uma análise cuidadosa do parágrafo terceiro do artigo $3^{\circ}$ e do artigo $7^{\circ}$ do Decreto de criação do Reuni deixa claro em que termos ocorrerá esta "expansão", pois "o atendimento aos planos é condicionado à capacidade orçamentária e operacional do MEC" e "as despesas decorrentes deste processo devem estar circunscritas às dotações orçamentárias consignadas anualmente ao MEC". (Lima, 2009, p. 92)

Assim, promulga o governo no PDE de 2007 que mais que um simples programa, ou "abertura de espaço orçamentário", o Reuni teria a capacidade de 
incentivar que cada instituição federal encontrasse de maneira autônoma seu caminho, já que, “em plena revolução científica, as fronteiras entre áreas do conhecimento tornam-se tênues e novas possibilidades de formação vão se delineando" (Brasil, 2007c, p. 28). Ou seja, nesta passagem, observamos que 0 governo incentiva que as áreas de pesquisa e as pós-graduações entrem de vez neste processo, incrementando, se possível, a base de apoio orçamentária e a inserção no processo de "revolução científica".

Na sequência, na citação abaixo, fica claro este intuito já que a "estrutura universitária deve estar à altura dos novos desafios da ciência". Assim, percebemos que há uma intrínseca ligação entre a reformulação das universidades e o desenvolvimento da área de Ciência \& Tecnologia. 0 novo Ministério da Ciência se chama Ministério da Ciência, Tecnologia e Inovação (MCTI) e está cada vez mais interligado ao Ministério da Educação (MEC), de acordo com o sitio do MEC na internet:

Uma das formas mais eficazes de incentivar as pesquisas é a partir da redução fiscal das empresas que investirem em projetos desenvolvidos por instituições públicas. 0 sentido dessa medida é aproximar o setor produtivo e industrial da pesquisa acadêmica aplicada, de acordo com o que está determinado pela Lei $n^{0} 11.487$, de incentivo à ciência e tecnologia, sancionada em 2007.

A exata compreensão dos fins do programa, portanto, exige atenção quanto aos meios a serem empregados: a expansão dos cursos noturnos, a ampliação da mobilidade estudantil, a revisão da estrutura acadêmica e a diversificação das modalidades de graduação. Itinerários rígidos, desperdício de créditos, imobilidade e especialização precoce são incompatíveis com uma estrutura universitária à altura dos novos desafios da ciência. A reestruturação que se espera, portanto, é acadêmica e, como tal, qualitativa. (Brasil, 2007c, p. 28)

O programa expõe claramente que se faz necessária a interligação dos programas de ciência à pesquisa universitária, ou seja, a construção de um sistema de apoio entre universidades e setor produtivo.

O programa Reuni, neste sentido, é uma plataforma, supostamente, ousada de reestruturação das universidades federais, mas que usa ou vincula, como já dito, o financiamento do programa de cada universidade às metas propostas pelo MEC. Há que se notar que a expansão proposta pelo governo em cada universidade exige um esforço grandioso de cada uma das instituições e há a possibilidade de estas não conseguirem cumprir as metas estabelecidas; assim, o MEC poderia suspender investimentos e recursos de maneira unilateral.

A autonomia universitária estaria ferida, portanto, quando o MEC se coloca como guardião dos cumprimentos das metas estabelecidas, mas os recursos 
não estão concretamente disponíveis para as universidades federais. E o discurso oficial, ao mesmo tempo que propõe suas metas e contratos de gestão heterônomos, oculta este caráter e busca se legitimar na proclamação de noção de uma "expansão democrática":

Em linha com proposta da Associação Nacional dos Dirigentes das Instituições Federais de Ensino Superior (Andifes), feita em 1997, o Reuni, mediante investimento maciço na educação superior, pretende melhorar os indicadores das instituições federais de educação superior, projetando alcançar um milhão de matrículas de graduação. 0 Reuni permite uma expansão democrática do acesso ao ensino superior, o que aumentará expressivamente o contingente de estudantes de camadas sociais de menor renda na universidade pública. (Brasil, 2007c, p. 27)

Percebemos mais uma vez que o discurso oficial de formulação do programa está na esfera da ideologia quando promulga a "democratização" e o "expressivo aumento de estudantes de camada sociais de menor renda". Está mais para propaganda do que para o estabelecimento de uma política pública para a educação superior. Como é possível afirmar que o Reuni permite uma expansão democrática antes de implantar o programa e auferir seus resultados concretos? Qual o intuito de inserir uma frase como esta na implantação do programa? Esta é a face ideológica praticada pelo governo e pelo MEC. E os documentos oficiais, apesar de se referirem ao qualitativo, primam por apontar dados quantitativos, como se fossem, per si, evidências da democratização.

A tabela 3 mostra, por exemplo, que, apesar dos esforços, o número de matrículas de graduandos presenciais com idade de 18 a 24 anos ainda é abaixo do esperado, equivalendo a $14.35 \%$ do total da população na faixa etária de 18 e 24 anos. 0 governo esperava chegar, ao início da década dos anos 2010, em $20 \%$ de matrículas no ensino superior nesta faixa etária. Além desse dado, percebese que nitidamente a grande parte destes estudantes está concentrada na região Sudeste, onde o percentual de matriculandos entre 18 e 24 anos sobe para $17.05 \%$ da população nesta faixa etária. Nesta mesma faixa etária, na região Nordeste, apenas $9.49 \%$ dos jovens estavam matriculados no ensino superior, evidenciando as desigualdades sociais e econômicas marcantes no território brasileiro, ou o desenvolvimento desigual e combinado da educação superior brasileira, destacando a educação superior no setor privado como preponderante (Cunha, 2004), como observado na tabela 4 abaixo. 
Tabela 3 - Distribuição de matrículas de graduação presencial (todas as idades e com idades de 18 a 24 anos) e população da faixa etária de 18 a 24 anos - Brasil e regiões geográficas - 2011).

\begin{tabular}{|c|c|c|c|c|c|c|c|c|}
\hline \multirow[b]{2}{*}{$\begin{array}{c}\text { Brasil// } \\
\text { Regiões } \\
\text { Geográficas }\end{array}$} & \multicolumn{4}{|c|}{ Pesquisa Nacional por Amostra de Domicílios (IBGE) } & \multicolumn{4}{|c|}{ Censo da Educação Superior (Inep) } \\
\hline & $\begin{array}{c}\text { População } \\
\text { (18 a } 24 \text { anos) }\end{array}$ & $\%$ & $\begin{array}{l}\text { Frequenta Curso } \\
\text { de Graduação } \\
\text { (18 a } 24 \text { anos) }\end{array}$ & $\%$ & $\begin{array}{l}\text { Matrículas de } \\
\text { Graduação } \\
\text { Presencial }\end{array}$ & $\%$ & $\begin{array}{c}\text { Matrículas de } \\
\text { Graduandos } \\
\text { Presenciais com Idade } \\
\text { de } 18 \text { a } 24 \text { anos }\end{array}$ & $\%$ \\
\hline Brasil & 22.497 .453 & 100,0 & 3.283 .368 & 100,0 & 5.746 .762 & 100,0 & 3.229 .755 & 100,0 \\
\hline Norte & 2.098 .423 & 9,3 & 217.642 & 6,6 & 385.717 & 6,7 & 186.370 & 5,8 \\
\hline Nordeste & 6.399 .491 & 28,5 & 664.870 & 20,2 & 1.138 .958 & 19,8 & 607.682 & 18,8 \\
\hline Sudeste & 9.113 .639 & 40,5 & 1.471 .314 & 44,8 & 2.755 .635 & 48,0 & 1.554 .273 & 48,1 \\
\hline Sul & 3.128 .684 & 13,9 & 582.965 & 17,8 & 929.446 & 16,2 & 570.293 & 17,7 \\
\hline Centro-Oeste & 1.757 .216 & 7,8 & 346.577 & 10,6 & 537.006 & 9,3 & 311.137 & 9,6 \\
\hline
\end{tabular}

Fonte: Brasil/MEC, 2013, p. 50.

Mas os números apresentados podem ser interpretados numa perspectiva distinta da oficial. Em relação ao número de matrículas, relacionadas na tabela 4, percebe-se que, entre os anos 2010 e 2011, o sistema público federal atingiu o número de 1.032 .936 de matrículas; incluindo nestes números todas as instituições de ensino superior público federal, apenas as universidades federais somaram 929.847 matriculas e, portanto, os institutos e escolas federais somam 103.089 alunos.

De qualquer maneira, este número representa $15.3 \%$ do total de matrículas no ensino superior no Brasil. 0 sistema público, como um todo, soma 1.773 .315 de matrículas, o que representa $26.3 \%$ de todo sistema de ensino superior no Brasil. Ou seja, as universidades, centros universitários e faculdades privadas somam 4.966 .374 matrículas, o que representava $73.7 \%$ de todas as matrículas em ensino superior no Brasil. Assim, mesmo com uma expansão acelerada do sistema público federal de ensino superior, haverá uma diferença quantitativa significante do número de matrículas no ensino público em relação ao ensino privado. 
Tabela 4 - número e percentual de matrículas, ingressos (todas as formas e processo seletivo) e concluintes de graduação (presenciais e a distancia), segundo a categoria administrativa - Brasil - 2010 - 2011.

\begin{tabular}{|c|c|c|c|c|c|c|c|c|c|c|c|}
\hline \multirow{3}{*}{ Ano } & \multirow{3}{*}{$\begin{array}{c}\text { Categoria } \\
\text { Administrativa }\end{array}$} & \multirow{2}{*}{\multicolumn{2}{|c|}{ Matrículas }} & \multicolumn{6}{|c|}{ Ingressos } & \multirow{2}{*}{\multicolumn{2}{|c|}{ Conduintes }} \\
\hline & & & & \multicolumn{2}{|c|}{ Total } & \multicolumn{2}{|c|}{ Por Processo Seletivo } & \multicolumn{2}{|c|}{ Outras Formas } & & \\
\hline & & Total & $\%$ & Total & $\%$ & Total & $\%$ & Total & $\%$ & Total & $\%$ \\
\hline \multirow{6}{*}{2010} & Total & 6.379 .299 & 100,0 & 2.182 .229 & 100,0 & 1.922 .240 & 100,0 & 259.989 & 100,0 & 973.839 & 100,0 \\
\hline & Pública & 1.643 .298 & 25,8 & 475.884 & 21,8 & 443.292 & 23,1 & 32,592 & 12,5 & 190.597 & 19,6 \\
\hline & Federal & 938.656 & 14,7 & 302.359 & 13,9 & 279.811 & 14,6 & 22.548 & 8,7 & 99.945 & 10,3 \\
\hline & Estadual & 601.112 & 9,4 & 141.413 & 6,5 & 135.463 & 7,0 & 5.950 & 2,3 & 72.530 & 7,4 \\
\hline & Municipal & 103.530 & 1,6 & 32.112 & 1,5 & 28.018 & 1,5 & 4.094 & 1,6 & 18.122 & 1,9 \\
\hline & Privada & 4.739 .001 & 74,2 & 1.706 .345 & 78,2 & 1.478 .948 & 76,9 & 227.397 & 87,5 & 783.242 & 80,4 \\
\hline \multirow{6}{*}{2011} & Total & 6.739 .689 & 100,0 & 2.346 .695 & 100,0 & 2.093 .368 & 100,0 & 253.327 & 100,0 & 1.016 .713 & 100,0 \\
\hline & Pública & 1.773 .315 & 26,3 & 490.680 & 20,9 & 457.552 & 21,9 & 33.128 & 13,1 & 218.365 & 21,5 \\
\hline & Federal & 1.032 .936 & 15,3 & 308.504 & 13,1 & 285.985 & 13,7 & 22.519 & 8,9 & 111.157 & 10,9 \\
\hline & Estadual & 619.354 & 9,2 & 146.049 & 6,2 & 139.872 & 6,7 & 6.177 & 2,4 & 87.886 & 8,6 \\
\hline & Municipal & 12025 & 1,8 & 36.127 & 1,5 & 31.695 & 1,5 & 4.432 & 1,7 & 19.322 & 1,9 \\
\hline & Privada & 4.966 .374 & 73,7 & 1.856 .015 & 79,1 & 1.635 .816 & 78,1 & 220.199 & 86,9 & 798.348 & 78,5 \\
\hline \multirow{6}{*}{$\begin{array}{l}\Delta \% \\
(2010- \\
2011)\end{array}$} & Total & 5,6 & & 7,5 & & 8,9 & & & & 4,4 & \\
\hline & Pública & 7,9 & & 3,1 & & 3,2 & & & & 14,6 & \\
\hline & Federal & 10,0 & & 2,0 & & 2,2 & & & & 11,2 & \\
\hline & Estadual & 3,0 & & 3,3 & & 3,3 & & & & 21,2 & \\
\hline & Municipal & 16,9 & & 12,5 & & 13,1 & & & & 6,6 & \\
\hline & Privada & 4,9 & & 8,8 & & 10,6 & & & & 1,9 & \\
\hline
\end{tabular}

Fonte: Brasil/MEC, 2013, p. 52.

Os números corroboram, portanto, a análise citada abaixo de, apesar de não ser recente o processo de privatização da educação superior no Brasil, nos últimos governos, a partir de 1995 até 2010, segundo nossa análise, este processo se concretiza de forma mais evidente. Observamos que, entre 2010 e 2011, 73.7\% das matrículas eram em instituições privadas; os interesses e a atuação das empresas ligadas à educação superior privada no Brasil, naquele período citado, aumentaram consideravelmente, tanto que o mercado, nesta área, se tornou extremamente competitivo com a atuação de empresas e capitais estrangeiros.

Mas não apenas pelos números, como também pela maneira da administração pública de organizar a educação superior, percebe-se uma mudança de enfoque nas universidades públicas da formação e universalidade lensino, pesquisa e extensão) para a instrução para o mercado e o ensino terciário. 0 Reuni enfatiza esta mudança, segundo nosso entendimento do programa e conforme análise exposta abaixo que versa sobre parte deste processo: 
Todavia, é a partir da década de 1990 que se inicia, no Brasil, um consistente processo de redução de gastos públicos federais para o conjunto das instituições federais de ensino superior (Ifes) e se desencadeia a retomada, em grau muito mais aprofundado que na década de 1970, sob a ditadura militar, da privatização desse nível de ensino. Assim, muito embora a privatização da educação superior não se restrinja aos dois últimos governos (o de Fernando Henrique Cardoso de 1995 a 2002 e o de Lula da Silva, a partir de 2003), foi neste período que ganhou um curso extraordinário, já que ambos aplicaram a máxima neoliberal, segundo a qual deve haver deserção do Estado de seu necessário protagonismo na implementação da universidade como um bem público e direito de cidadania. (Mancebo, 2010, p.75)

Está se concretizando no Brasil, na área do ensino superior, um processo de mão-dupla de mercantilização: em primeiro momento, a expansão acelerada das instituições privadas e a inserção da lógica da educação superior como uma mercadoria implicam um processo de privatização; em segundo momento, e mais importante, as relações do Estado com a área da educação, e da educação superior de modo mais específico, passam a ser regidas a partir da lógica da produção e reprodução de capital.

O Estado como um todo passa a ser administrado desta maneira, esta é a face mais predatória deste processo. Assim, todos os instrumentos de política pública, excetuando-se os programas com viés assistencialista e emergenciais, ou seja, pontuais e não estruturais, são implantados com foco na "otimização" e "eficiência" do trabalho.

0 trabalho imaterial e intelectual, como o dos professores, está se integrando cada vez mais, junto com a apropriação da produção cientifica, pela lógica do mercado, a esta forma de trabalho produtivo (Marx, 2011). Assim, e a partir de uma série de mediações, estamos atingindo um estágio das transformações das relações de trabalho, com o regime de acumulação flexível (Harvey, 1996) que insere o trabalho do professor no processo de produção e reprodução de maisvalia.

Percebemos este processo nas universidades, principalmente na atuação de professores-pesquisadores, aqueles que estão intrinsicamente ligados à esfera da produção científica e tecnológica, mas que voltam os objetivos de suas atividades à produção para o mercado: este processo, em última análise, traz alienação frente ao seu próprio trabalho, condição sine qua non para a transformação destas atividades em trabalho produtivo.

Não obstante, o estranhamento frente à atividade alienada engendra contradições, assim como a efetivação do trabalho imaterial em trabalho produtivo apenas se dá sob uma série de mediações. De qualquer forma, compreendemos que se efetiva nas mudanças de identidade da universidade e de suas práticas sob os eixos da reforma do Estado e das novas formas de produção e valoração do capital. 
A compreensão das mudanças da identidade da instituição escolar - lugar da prática da educação básica - da instituição universitária e do trabalho do professor (cujo trabalho é imaterial e superqualificadol deve ocorrer por meio do entendimento de dois grandes eixos, dentre outros: o primeiro consiste na reforma do Estado posta em movimento em 1995 e em curso até os dias atuais; o segundo realiza-se nas mudanças na produção e valoração do capital. 0 primeiro realiza-se por meio das reformas das instituições republicanas, da reorganização da sociedade civil e da mudança da sociabilidade do ser humano neste momento do capitalismo; o segundo tem como principais orientações, de um lado, a reestruturação produtiva, que teve seu início sistematizado no Brasil na primeira metade da década de 1980 , e de outro, a transformação radical no trabalho imaterial superqualificado, ambos no contexto da acumulação flexível. Esta última condensa as formas "pretéritas" e atuais de exploração do trabalho, atualizadas por novas e eficientes formas de controle e valorização do capital. (Silva Junior, 2009, p. 148)

Desta maneira, estas transformações do setor público e, portanto, a implantação destes programas vão atingir também a esfera do trabalho público e, mais especificamente, o trabalho docente nas universidades federais. Estão inseridos no programa Reuni maneiras e exigências diretas para o aumento da produtividade e "otimização" dos recursos humanos nestas instituições, e este é outro processo que já se iniciou há algum tempo.

0 aumento da exploração do trabalho docente, no Brasil, ademais como em todos os países latinos, deu-se em especial pela flexibilidade registrada nos regimes de trabalho e consequente quebra da carreira docente, onde ela existia. Do total de docentes cadastrados pelo censo do Inep (MEC/Inep, 2006b), apenas 16,9\% trabalham em regime de dedicação exclusiva e 18,6\% em tempo integral. [...]

Todavia, a flexibilização não se restringe ao tipo de contrato que é oferecido, pois em nome deste princípio tem-se assistido a um aumento substantivo do trabalho docente, um processo ainda inconcluso e que é objetivado tanto na educação privada, quanto na pública. 0 estratégico dessas alterações é que os novos protocolos destinados aos docentes envolvem mecanismos que têm por alvo a intensificação e extensão do trabalho, relacionando-o às demandas e/ou lógica de mercado. [...]

A partir de 2007, por exemplo, com a aprovação do Programa de Reestruturação e Expansão das Universidades Federais (Reuni, Decreto Presidencial nº 6.096 de 24 de Abril de 2007), até o custeio de atividades básicas dependerá de contratos de gestão com o Estado. Com este Programa - operacionalização, na prática, dos contratos de gestão, ensaiados desde o governo de FHC -, recursos somente serão disponibilizados se a universidade alcançar metas de expansão. (Mancebo, 2010, p. 78-81)

Assim esta expansão se dá, também, ao custo de intensificação do trabalho docente, quevem acumulando, progressivamente, funções técnico-administrativas, além de suas funções docentes e de pesquisa, na graduação e na pós-graduação. E a relação professor-aluno que, segundo nossa perspectiva, redunda em 
intensificação do trabalho e massificação do ensino é apontada como melhor aproveitamento de recursos pelo discurso oficial. Esta é mais uma consequência do processo de mercantilização das relações de trabalho que se configuram nas transformações do Estado no contexto de mundialização do capital. Os artigos abaixo versam sobre a regulamentação das horas de trabalho docente e o número de discentes por sala:

A relação de dezoito estudantes de graduação presencial por professor foi fixada com base nas determinações contidas na Lei de Diretrizes e Bases da Educação Nacional (Lei no 9.394/1996), no que se refere à carga horária dos professores (art. 57), estimando-se salas de aulas com 45 alunos de graduação e uma carga horária discente de aproximadamente vinte horas semanais. (BRASIL, 2007, página 4)

Art. 57. Nas instituições públicas de educação superior, o professor ficará obrigado ao mínimo de oito horas semanais de aulas. (Brasil, 1996, p.23)

Nesta passagem acima das Diretrizes Gerais do Reuni do MEC de 2007, há esta nota de rodapé indicando que, na LDB de 1996, se instituiu a carga horária docente mínima, e esta é de 8 horas semanais, e que se estimando uma carga docente de 20 horas e turmas de 45 alunos na graduação se conseguiria atingir uma das metas do programa de "elevação gradual da taxa de conclusão média dos cursos de graduação presenciais para noventa por cento e da relação de alunos de graduação em cursos presenciais por professor para dezoito, ao final de cinco anos". (Brasil, 2007b, p.4)

Neste sentido, o governo não percebe ou não reconhece que seja uma sobrecarga de trabalho, além das capacidades físicas e intelectuais do corpo docente das universidades federais, o aumento da relação aluno-professor (RAP) e a estimativa da carga horária docente na sala de aula de 20 horas, ou seja, cinco disciplinas de quatro créditos por semestre, em um sistema em que já há uma extensificação acúmulo de funções e aumento da carga horária de trabalho - das tarefas a serem realizadas pelos docentes, em que cada turma teria 45 alunos em média, em que há uma insuficiência de técnicos-administrativos no auxilio da administração dos departamentos, e há as exigências da Coordenação de Aperfeiçoamento de Pessoal de Nível Superior (Capes) pelo aumento da produtividade de pesquisa.

Ademais, a recomendação de uma meta a priori para a carga horária em sala de aula por professor fere o principio da autonomia universitária. 0 governo promulgou que cada instituição e que cada curso poderiam estabelecer suas próprias diretrizes para a reformulação curricular, mas coloca em suas Diretrizes Gerais do Reuni esta observação acerca da carga horária em sala de aula. Desta maneira, não preserva a possibilidade de cada curso e cada departamento, com suas especificidades, gerirem e promoverem suas próprias transformações. 
Vejamos como evoluiu entre 2007 e 2011 o número de matrículas em relação à evolução do número de docentes e perceberemos que o Ministério da Educação (MEC) incentiva relativamente a maior expansão do número de alunos em relação à expansão do número de professores.

Tabela 5 - Evolução do número de docentes em relação à expansão do número de vagas em instituições federais - Brasil - 2007 A 2011.

\begin{tabular}{|c|c|c|c|}
\hline & 2007 & 2011 & $\Delta \% 2007-2011$ \\
\hline Número de matrículas & 641.094 & 1.032 .936 & $61,12 \%$ \\
\hline $\begin{array}{l}\text { Evolução do número } \\
\text { de docentes }\end{array}$ & 59.156 & $\begin{array}{c}90.388(\text { total }) \\
84.408(\mathrm{em} \\
\text { exercício })\end{array}$ & $\begin{array}{c}52,20 \% \text { (considerando o total } \\
\text { de docentes) }\end{array}$ \\
\hline $\begin{array}{l}\text { RAP (relação aluno- } \\
\text {-professor) }\end{array}$ & $\begin{array}{l}\text { 10,83 (alunos/ } \\
\text { professor) }\end{array}$ & $\begin{array}{l}\text { 11,42(alunos/pro- } \\
\text { fessor) 12,23 (em } \\
\text { exercício) }\end{array}$ & $\begin{array}{c}12,92 \% \text { (diferença da relação } \\
\text { alunos por professor) }\end{array}$ \\
\hline
\end{tabular}

Fonte: Elaboração própria, segundo dados do Inep.

Considerando o total do número de docentes no sistema federal de educação superior e o número de matrículas no mesmo período 2007-2011, anos em que - Programa Reuni estava sendo implantado em grande parte das universidades federais, percebe-se que o governo consegue "aumentar/melhorar", segundo sua lógica, ainda que não tão intensamente, o índice de aluno-professor (RAP). Houve um incremento de $12,92 \%$ na relação de alunos por professor de 2007 para 2011, segundo dados do Inep expostos na tabela acima. Mas, no primeiro relatório do Reuni de 2009, produzido pelo MEC, esta instituição, sem apontar números, afirma [...] “No primeiro ano de execução foi possível observar uma média entre as relações das universidades de 17,8 alunos por professor, o que aponta para 0 cumprimento da meta". (Brasil/MEC, 2009 p. 7)

\section{Conclusão}

O Reuni em essência é um programa que, apesar de propor a expansão e a reestruturação das universidades federais no Brasil e, de certa forma, consolidar estas metas, é muito mais que um simples programa, pois, como pano de fundo para a consolidação destas metas, traz consigo a concretização da inserção do Brasil no contexto da mundialização do capital. Esta concretização se dá por meio de mecanismos que estão subjacentes às propostas de primeiro plano 
do programa. Ou seja, não é uma meta declarada e assumida do Reuni que as universidades sejam administradas e financiadas com a lógica da administração gerencial, mas esta intenção se materializa.

O Governo e o MEC foram bem sucedidos na propaganda política que foi possível de se estabelecer com a implantação do Reuni. Ou seja, a retórica institucional, de forma mais ou menos direta, foi absorvida pelos docentes que fizeram parte desta reestruturação da universidade, mesmo com a efetivação de sobrecarga e intensificação do trabalho. Por esta razão, argumentamos que o programa concretizou parte de sua materialidade, ou seja, há uma real dimensão de mudanças físicas nas universidades, não é apenas discurso. Mas, por meio do discurso, o governo alcançou mais êxito do que o programa obteve na realidade.

Em segundo momento, percebemos claramente que a organização micropolítica das universidades, em suas administrações e em seus departamentos, estabelece um jogo dialético na implantação das políticas públicas para a educação superior. Assim, parte das metas do Reuni são renegociadas no momento de sua implantação em cada unidade acadêmica. A situação política e econômica de cada universidade, sua maior ou menor inserção no cenário brasileiro de produção acadêmica e científica, seu papel na difusão de tecnologias, sua maior ou menor inserção no setor industrial-produtivo na região em que atua e as demandas da classe docente que administram aquela universidade, aquele centro e aquele curso, são características que influenciam diretamente na implantação dos programas para o ensino superior público federal. Há uma cena política efervescente e interessada, ideologicamente direcionada segundo suas pretensões acadêmicas, políticas e econômicas.

Esta política de Estado direciona as universidades federais para uma maior ligação e para a interdependência destas com o setor industrial-produtivo brasileiro. São programas como o Reuni que demonstram que o governo e o Estado brasileiros, independentemente de qual partido esteja no governo, assumem a necessidade da inserção completa do Brasil no processo de mundialização do capital. Assumem o Brasil como um país que necessita ser atraente ao capital produtivo e financeiro internacionais, um país dependente tecnologicamente, e que pode, a partir de desenvolvimento científico e tecnológico direcionados, cumprir um papel emergente, em outras palavras, semiperiférico, na economia mundial. O Reuni auxilia na concretização desta dimensão econômico-social do Brasil: um país com mão-de-obra qualificada para a reprodução de tecnologia, inserido perifericamente na produção de tecnologia de ponta, com capacidade limitada - com a busca para o incremento - para o crescimento de seu setor industrial e com possibilidades modestas, a curto e médio prazos, de transformação da realidade social, ou seja, do quadro de péssima distribuição de renda no qual a sociedade brasileira se encontra. 


\section{Referências}

Brasil. Lei no 9.394. Lei de diretrizes e bases da educação. Brasília, 1996.

Decreto $n^{0}$ 6096, de 24 de abril de 2007. Programa de Apoio a Planos de Reestruturação e Expansão das Universidades Federais - REUNI. Brasília, 2007 a. Disponível em: <http://www.mec.gov.br>. Acesso em: 07 set. 2011.

. REUNI - Diretrizes Gerais. Brasília, 2007 b. Disponível em: <http://portal. mec.gov.br/sesu/arquivos/pdf/diretrizesreuni.pdf>. Acesso em: 07 set. 2011.

. Plano de desenvolvimento da Educação: razões, princípios e programas (PDE). Brasília, 2007 c. Disponível em: <http://portal.mec.gov.br/arquivos/livro/ livro.pdf>. Acesso em: 11 fev. 2012.

REUNI 2008 - Relatório de Primeiro Ano. Brasília, 2009. Disponível em: <http://www.mec.gov.br>. Acesso em: 07 set. 2011.

Resumo técnico: censo da educação superior 2011. Brasília, 2013.

Lei de incentivo à pesquisa. Disponível em: <http://portal.mec.gov.br/ index.php/?option=com_content\&view=article\&id=12311>. Acesso em: 11 nov. 2013.

CUNHA, Luiz Antônio. A universidade reformanda - o golpe de 1964 e a modernização do ensino superior. Rio de Janeiro, Francisco Alves, 1988.

FERREIRA, Suely. Reforma da educação superior no Brasil e na Europa: em debate novos papéis sociais para as universidades. 2010. Disponível em: <http://www. anped11.uerj.br/reformadaeducacaosuperior.pdf>. Acesso em: 31 out. 2013.

HARVEY, David. A condição pós-moderna. Uma pesquisa sobre as origens da mudança cultural. São Paulo: Edições Loyola, 1994.

LIMA, Kátia Regina de Souza. Universidades federais e o REUNI: alterações nas funções da universidade pública brasileira. Revista Advir, Rio de Janeiro, n023, dezembro de 2009, p. 20-27. Disponível em: <http://www.asduerj.org.br/images/ advir/pdf_revista/Advir23online.pdf >. Acesso em: 11 set. 2012.

MANCEBO, Deise. Trabalho docente na educação superior brasileira: mercantilização das relações e heteronomia acadêmica. Universidade de Minho, 23(2), pp. 73-91. Revista Portuguesa de Educação, 2010.

MARX, Karl. 0 capital: crítica da economia política. 29. ed. Rio de Janeiro: Civilização Brasileira, 2011.

SILVA JR, João dos Reis. 0 professor pesquisador nas universidades públicas no contexto da internacionalização do capital: a produtividade do trabalho imaterial superqualificado. 22 (jan-jun). Revista Portuguesa de Educação, 2009. 
Recebido em agosto de 2014

Aprovado em setembro de 2014

André Moura Blundi Filardi é mestre em Educação pela Universidade Federal de São Carlos (UFSCar). E-mail: filexisdyahoo.com.br 